\title{
A randomised, double blind, placebo controlled, multicentre trial of combination therapy with methotrexate plus ciclosporin in patients with active psoriatic arthritis
}

\author{
A D Fraser, A W R van Kuijk, R Westhovens, Z Karim, R Wakefield, A H Gerards, \\ R Landewé, S D Steinfeld, P Emery, B A C Dijkmans, D J Veale
}

See end of article for authors' affiliations

Correspondence to:

Dr A D Fraser,

Rheumatology and

Rehabilitation Research

Unit, Old Nurses Home,

Great Georges Street,

Leeds, West Yorkshire LS1

3EX, UK; drsandyfraser@

aol.com

Accepted 27 October 2004

Published Online First

4 November 2004

\begin{abstract}
Objectives: To evaluate the safety and efficacy of adding ciclosporin A (CSA) to the treatment of patients with psoriatic arthritis ( $\mathrm{Ps} A$ ) demonstrating an incomplete response to methotrexate (MTX) monotherapy. Methods: In a 12 month, randomised, double blind, placebo controlled trial at five centres in three countries, 72 patients with active $\mathrm{PsA}$ with an incomplete response to MTX were randomised to receive either CSA ( $n=38$ ) or placebo $(n=34)$. Patients underwent full clinical and radiological assessment and, in addition, high resolution ultrasound (HRUS) was performed at one centre. An intention to treat (last observation carried forward) analysis was employed.

Results: Some significant improvements were noted at 12 months in both groups. However, in the active but not the placebo arm there were significant improvements in swollen joint count, mean (SD), from 11.7 (9.7) to 6.7 (6.5) $(p<0.001)$ and $C$ reactive protein, from $17.4(14.5)$ to $12.7(14.3) \mathrm{mg} / \mathrm{l}(\mathrm{p}<0.05)$ as compared with baseline. The Psoriasis Area and Severity Index (PASI) score improved in the active group (2 (2.3) to $0.8(1.3))$ as compared with placebo (2.2 (2.7) to $1.9(2.8)), \mathrm{p}<0.001$, and synovitis detected by HRUS (33 patients, 285 joints) was reduced by $33 \%$ in the active group compared with $6 \%$ in the placebo group $(p<0.05)$. No improvement in Health Assessment Questionnaire or pain scores was detected.

Conclusions: Synovitis detected by HRUS was significantly reduced. Combining CSA and MTX treatment in patients with active PsA, and a partial response to MTX, significantly improves the signs of inflammation but not pain or quality of life.
\end{abstract}

$\mathrm{P}$ soriatic arthritis (PsA), usually seronegative for rheumatoid factor, is the second most common arthritis after rheumatoid arthritis (RA), accounting for $10-15 \%$ of patients presenting to early arthritis clinics. ${ }^{2}$ Psoriasis affects an estimated $2 \%$ of the general population, and arthritis complicates this in up to $10 \%$ of cases. ${ }^{3}$ Until recently, compared with RA, PsA was considered to be a benign arthropathy; however, the evidence suggests that PsA may result in a destructive deforming arthropathy despite active treatment. ${ }^{45}$ Severe functional limitation may occur and a significant increase in the standardised mortality ratio in patients with PsA as compared with the general population has been reported. ${ }^{4}{ }^{6}$

Development of a uniform approach to the treatment of PsA has been hampered by many factors, including the complex interaction of skin and joint disease, a reluctance to use disease modifying antirheumatic drugs (DMARDs) and, importantly, by a lack of evidence of the efficacy of these treatments from controlled studies. Currently, initial treatment for PsA consists of non-steroidal anti-inflammatory drugs (NSAIDs) and local steroid injections, with DMARDs being reserved for NSAID resistant or progressively destructive disease. Methotrexate (MTX), sulfasalazine, and ciclosporin A (CSA) are the most widely used DMARDs at present, ${ }^{7}$ but many patients still fail to respond adequately.

MTX is highly effective in the treatment of skin psoriasis, ${ }^{8}$ and there is evidence from small, open studies supporting a role in PsA. ${ }^{9-13}$ Similarly, CSA is effective and widely used in the control of difficult psoriasis and there is evidence to support its use in PsA.[14-19] The use of these agents as monotherapy in PsA is due, in part, to their potential benefits for both skin and joint disease, and they are familiar to both dermatologists and rheumatologists alike.

Combination therapy with CSA and MTX has been shown to result in a clinically important improvement with no substantial increase in side effects in RA. ${ }^{20}$ There is uncontrolled evidence in a pilot study for additive efficacy without an increase in serious side effects in PsA. ${ }^{21}$

This multicentre, double blind, placebo controlled, randomised trial was designed to assess combination therapy of MTX plus CSA for the treatment of patients with active PsA.

\section{PATIENTS AND METHODS}

\section{Patients}

Outpatients fulfilling criteria for the diagnosis of PsA, ${ }^{1}$ were recruited from five clinical centres: Leeds, Amsterdam, Leuven, Maastricht, and Brussels, after written informed consent was obtained. Local ethics committee approval for the study was obtained at each of the centres. Patients aged between 18 and 70 years were included if they had a minimum disease duration of 24 weeks, evidence of skin

Abbreviations: CRP, C reactive protein; CSA, ciclosporin A; DMARDs, disease modifying antirheumatic drugs; $E S R$, erythrocyte sedimentation rate; $H A Q$, Health Assessment Questionnaire; HRUS, high resolution ultrasound; MTX, methotrexate; NSAIDs, non-steroidal antiinflammatory drugs; PASI, Psoriasis Area and Severity Index; PsA, psoriatic arthritis; RA, rheumatoid arthritis; SJC, swollen joint count; TJC, tender joint count; TJI, tender joint index; VAS, visual analogue scale 
and/or nail psoriasis, and were seronegative for rheumatoid factor. Active PsA was defined as a minimum of three tender joints, and patients had to have had an incomplete response to a minimum of $15 \mathrm{mg}$ MTX weekly or lower if unable to tolerate a higher dose. Patients had to have been taking MTX treatment for at least 3 months before screening and the MTX dose had to have been stable for 1 month before screening. Patients were permitted to be taking oral prednisolone ( $\leqslant 10 \mathrm{mg} /$ day) or NSAIDs, or both, provided that the dose was stable for 1 month before baseline. Clinical subsets of PsA were not significantly different between groups and were defined as described by Veale et al. ${ }^{1}$ In both groups (MTX/CSA and MTX/placebo) the symmetric polyarthritis subgroup was most common $(53 \%$ and $61 \%$, respectively), followed by asymmetric oligoarthritis (44\% and $39 \%$, respectively). One patient in the MTX/CSA group had asymmetric oligoarthritis and ankylosing spondylitis and no patients in the study had arthritis mutilans or isolated distal interphalangeal joint disease.

Patients were excluded from the study if they had abnormal hepatic or renal function, blood dyscrasia, or severe cardiac or respiratory disease.

\section{Treatment groups and monitoring}

Patients were randomly assigned to receive CSA or placebo in addition to MTX. The initial dose of CSA was $2.5 \mathrm{mg} / \mathrm{kg} / \mathrm{day}$ and the dose was increased at weeks 4,8 , and 12 by $0.5 \mathrm{mg}$ / $\mathrm{kg} / \mathrm{day}$, to a maximum dose of $4 \mathrm{mg} / \mathrm{kg} /$ day. CSA safety was determined by renal dysfunction and hypertension. If the serum creatinine increased during the treatment period by $30 \%$ then the CSA dosage was reduced in accordance with a predetermined titration table. An increase in the mean diastolic blood pressure to between 95 and $110 \mathrm{~mm} \mathrm{Hg}$ at two consecutive visits triggered the introduction of an appropriate antihypertensive agent, and if this did not decrease below $95 \mathrm{~mm} \mathrm{Hg}$ by the next visit, then the study drug was reduced.

The dose of MTX was reduced by $50 \%$ if an increase in aspartate aminotransferase or alanine aminotransferase of twice the upper limit of normal occurred. CSA and MTX were discontinued and the patient withdrawn if two consecutive dose reductions failed to normalise the clinical variable triggering the dosage titration.

\begin{tabular}{|c|c|c|}
\hline & $\begin{array}{l}\text { Placebo } \\
(n=34)\end{array}$ & $\begin{array}{l}\text { Ciclosporin } \\
(n=38)\end{array}$ \\
\hline Women, No (\%) & $19(56)$ & $27(71)$ \\
\hline Age (years), mean (SD) & $47.1(10.8)$ & $46.8(11.5)$ \\
\hline $\begin{array}{l}\text { Race }(\%): \\
\text { Caucasian }\end{array}$ & $31(91)$ & $35(92)$ \\
\hline Asian & $2(6)$ & $3(8)$ \\
\hline Other & $1(3)$ & $0(0)$ \\
\hline Disease duration (months), mean (SD) & $42.4(41.9)$ & $40.8(33.0)$ \\
\hline Dactylitis, No (\%) & $7(21)$ & $7(18)$ \\
\hline Nail dystrophy, No (\%) & $22(65)$ & $22(58)$ \\
\hline Enthesitis, No (\%) & $6(18)$ & $9(24)$ \\
\hline Uveitis, No (\%) & $1(3)$ & $0(0)$ \\
\hline HLA-B27, No (\%) & $9(26)$ & $6(16)$ \\
\hline DR4, No $(\%)$ & $8(24)$ & $11(29)$ \\
\hline \multicolumn{3}{|l|}{ Concomitant treatment at baseline: } \\
\hline NSAIDs, No (\%) & $26(76)$ & 30 (79) \\
\hline Prednisolone ( $\leqslant 10 \mathrm{mg} /$ day), No (\%) & $0(0)$ & $2(5)$ \\
\hline Tender joint index, mean (SD) & $44.3(38.2)$ & $35.4(34.8)$ \\
\hline Tender joint count, mean (SD) & $28.3(19.2)$ & $22.6(15.9)$ \\
\hline Swollen joint count, mean (SD) & $11.7(8.6)$ & $11.7(9.7)$ \\
\hline CRP (mg/l), mean (SD) & $15.4(13.3)$ & $17.4(14.5)$ \\
\hline PASI score, mean (SD) & $2.2(2.7)$ & $2(2.3)$ \\
\hline Larsen score, mean (SD) & $36(28.7)$ & $33(27)$ \\
\hline
\end{tabular}

\section{Assessments}

Clinical assessments, ${ }^{22}$ including joint assessments based on a 68 joint model, were undertaken at baseline (week 0 ) and weeks 2, 4, 8, 12, 16, 20, 24, 30, 36, 42, and 48. The tender joint articular index was evaluated at all visits except weeks 16 and 36. If a joint was injected less than 3 months before screening then this was recorded and noted at each subsequent assessment, and if a joint required injection during the study, the joint was assessed before injection and the injection was noted and recorded at subsequent assessments.

The secondary efficacy measures were (a) tender joint count; (b) swollen joint count; (c) erythrocyte sedimentation rate (ESR) and/or C reactive protein (CRP; all visits); (d) change in the Psoriasis Area and Severity Index (PASI ${ }^{23}$ evaluated at weeks 4, 12, 24, 36, and 48; (e) change in patient assessment of pain (100 mm visual analogue scale (VAS)) at each visit; $(f)$ change in patient global assessment of disease activity (100 mm VAS) at each visit; $(g)$ change in physician global assessment of disease activity ( $100 \mathrm{~mm}$ VAS) at each visit; $(h)$ change in quality of life as assessed by the Health Assessment Questionnaire (HAQ) at weeks 24 and $48^{24}$; (i) change in Larsen and Dale damage score between baseline and weeks 24 and 48 as assessed by $x$ ray examination; $(j)$ high resolution ultrasound (HRUS) assessment of synovitis (at the Leeds site only).

$x$ Ray findings of the hands and feet were assessed by two musculoskeletal radiologists aware of the chronological order of the films but unaware of the patient's identity. Joint scoring was carried out in accordance with the Larsen and Dale method. ${ }^{25}$ In addition, patients at one centre had ultrasonography performed at baseline and study completion as part of the study protocol. An ATL HDI 3000 machine was used. The second to fifth metacarpophalangeal and proximal interphalangeal joints of the dominant hand were scanned by one blinded rheumatologist experienced in ultrasonography. Assessment for synovitis was undertaken as previously described and validated in PsA. ${ }^{26} 27$

\section{Statistical analysis}

The primary measure of efficacy was the change from baseline to final visit ( 12 months) in joint tenderness as measured by the modified Ritchie index. Published experience was taken into account ${ }^{182829}$ and response rates of $25 \%$ in the treatment arm and $5 \%$ in the placebo arm were employed as the basis of a sample size calculation. A sample size of 112 was calculated to have $80 \%$ power to detect a difference between the treatment groups with 5\% significance and a $20 \%$ dropout rate. The efficacy analysis was carried out on the intention to treat population which is defined as all patients who received the trial drug, provided baseline efficacy data, and from whom at least one measurement after baseline was obtained. The end point measurement for each randomised patient was the last postrandomisation measurement carried forward. The safety population were all patients receiving at least one dose of study drug. The Mann-Whitney U test was used to assess the statistical significance of differences between groups. Values of $\mathrm{p}<0.05$ were considered significant.

\section{RESULTS}

Seventy two consecutive patients underwent screening and 72 were randomised. Table 1 summarises the baseline characteristics of the patients; no significant differences were noted between the groups. The mean disease duration for PsA was only 3-4 years and of the 72 patients enrolled, 21/38 $(55 \%)$ in the MTX/CSA group and 23/34 (68\%) in the MTX/ placebo group completed the 12 month regimen of the study drug. 
Table 2 Outcomes of treatment groups during the 12 months study

\begin{tabular}{|c|c|c|c|c|}
\hline & \multicolumn{2}{|l|}{ Placebo } & \multicolumn{2}{|l|}{ Ciclosporin } \\
\hline & Baseline & 48 weeks & Baseline & 48 weeks \\
\hline TJI, mean (SD) & $44.3(38.2)$ & $27.4(27)^{\star *}$ & $35.4(34.8)$ & $23.4(37)^{\star *}$ \\
\hline TJC, mean (SD) & $28.3(19.2)$ & $19.7(17.9)^{* *}$ & $22.6(15.9)$ & 15. $3(16.5)^{\star *}$ \\
\hline SJC, mean (SD) & $11.7(8.6)$ & $7.9(5)$ & $11.7(9.7)$ & $6.7(6.5)^{* *}$ \\
\hline ESR (mm/1 st h), mean (SD) & $24.5(19.3)$ & $22.9(14.9)$ & $24.6(21.6)$ & $25.5(17.3)$ \\
\hline $\mathrm{CRP}(\mathrm{mg} / \mathrm{l})$, mean (SD) & $15.4(13.3)$ & $12.6(9)$ & $17.4(14.5)$ & $12.7(14.3)^{*}$ \\
\hline PASI, mean (SD) & $2.2(2.7)$ & $1.9(2.8)$ & $2(2.3)$ & $0.8(1.3)^{\star \star} t$ \\
\hline Patient global pain (VAS/cm), mean (SD) & $5.1(2.3)$ & $4.9(2.9)$ & $4.7(2.2)$ & $3.9(2.4)$ \\
\hline $\begin{array}{l}\text { Patient global disease activity (VAS/cm), } \\
\text { mean (SD) }\end{array}$ & $5.4(2.2)$ & $4.9(2.8)$ & $5.1(2.3)$ & $4.1(2.7)$ \\
\hline $\mathrm{HAQ}$, mean (SD) & $1.1(0.45)$ & $0.9(0.52)$ & $1.0(0.62)$ & $0.9(0.61)$ \\
\hline
\end{tabular}

Significant improvements were noted in both the MTX/ CSA and MTX/placebo groups between baseline and the end of the study, but significant differences between the groups were noted in the PASI score and synovitis detected by ultrasound. However, in the MTX/CSA group, significant clinical improvements from baseline were also detected in some measures which were not evident in the MTX/placebo group. Table 2 summarises these study outcomes.

The tender joint index (TJI) improved from 35.4 to 23.4 in the MTX/CSA group $(\mathrm{SD}=45.3, \mathrm{p}<0.001)$ and from 44.3 to 27.4 in the MTX/placebo group $(\mathrm{SD}=36, \mathrm{p}<0.001)$. Similarly, the tender joint count (TJC) improved significantly in the MTX/CSA group from 22.6 to $15.3 \quad(\mathrm{SD}=10.2$, $\mathrm{p}<0.001)$ and also in the MTX/placebo group 28.3 to 19.7 $(\mathrm{SD}=9.0, \mathrm{p}<0.001)$. However, the improvement in swollen joint count (SJC) from baseline was significant in the MTX/ CSA group, from 11.7 to $6.7(\mathrm{SD}=47, \mathrm{p}<0.001)$, but not in the MTX/placebo group. Similarly, CRP fell significantly in the MTX/CSA group from 17.4 to $12.7 \mathrm{mg} / \mathrm{l} \quad(\mathrm{SD}=9.9$, $\mathrm{p}<0.05$ ), but not in the MTX/placebo group. The PASI score of patients receiving MTX/CSA fell significantly compared with the score of patients in the MTX/placebo group from 2 to $0.8(\mathrm{SD}=1.9, \mathrm{p}<0.001)$. No changes were recorded in ESR between baseline and the end of the study in either group. Physician and patient global assessments of disease activity and pain VAS improved in both groups, with no betweengroups difference. Larsen scores of radiological damage increased in both groups: MTX/CSA group, mean (SD), 33 (27) to 34.6 (24); and MTX/placebo group, 36 (28.7) to 43.4 (33), (NS). Figure 1 shows these study outcomes.

HRUS assessment of joints for synovitis showed a significant reduction in the mean adjusted number of definite or probable synovitic joints detected for each person in the MTX/CSA group $(-2.5,95 \%$ confidence interval (CI) -4.07 to -1.01$)$ as compared with the MTX/placebo group $(-0.28,95 \%$ CI -1.67 to 1.1$)(\mathrm{p}<0.05)$. The overall number of joints with synovitis in the placebo group was 64/95 (67\%) at baseline and 58/95 (61\%) at 48 weeks. In the MTX/CSA
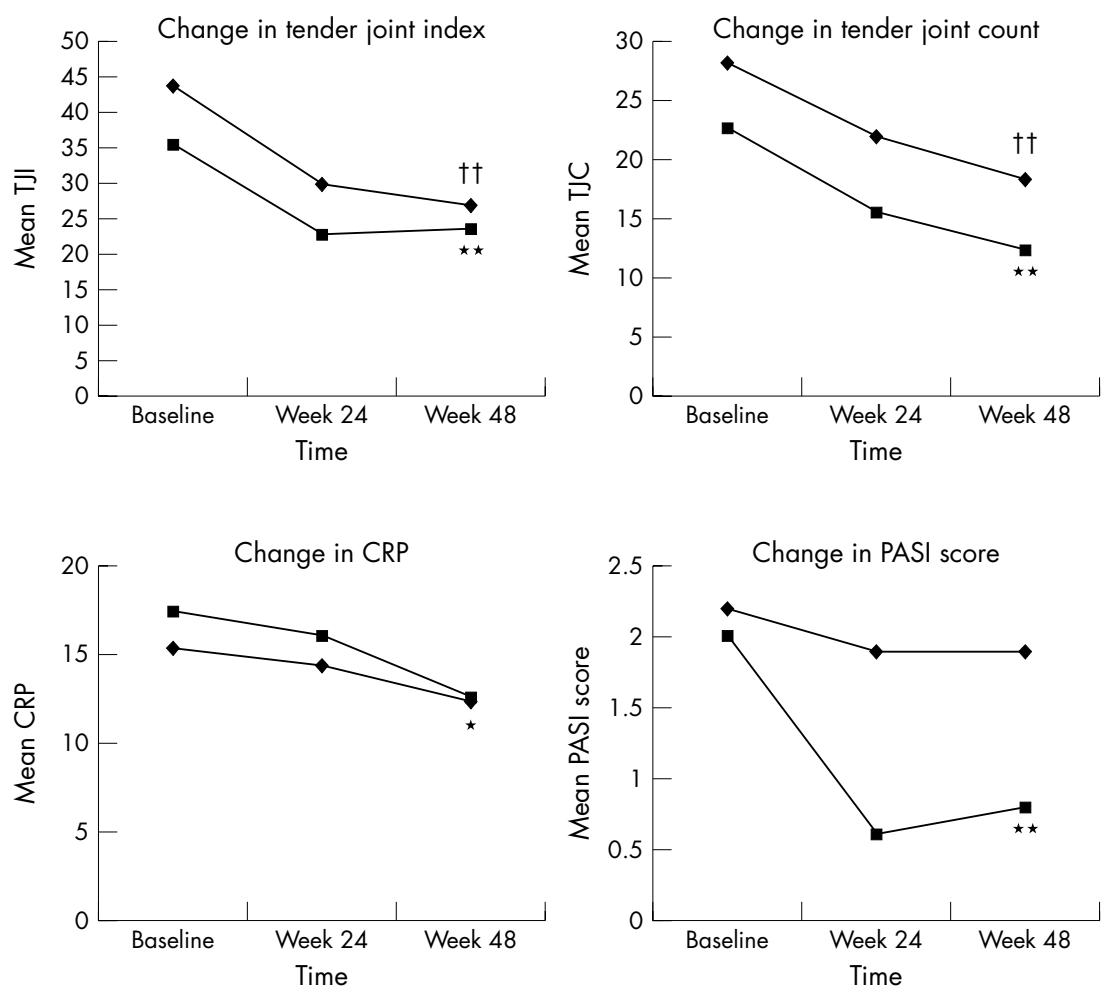

Figure 1 Changes in clinical, biochemical, and radiological measurements between baseline and 48 weeks. Significant changes from baseline are indicated ( ${ }^{*} p<0.05$ and ${ }^{* *} p<0.001$ for the active group; $\uparrow p<0.05$ and $+\uparrow p<0.001$ for the placebo group). 


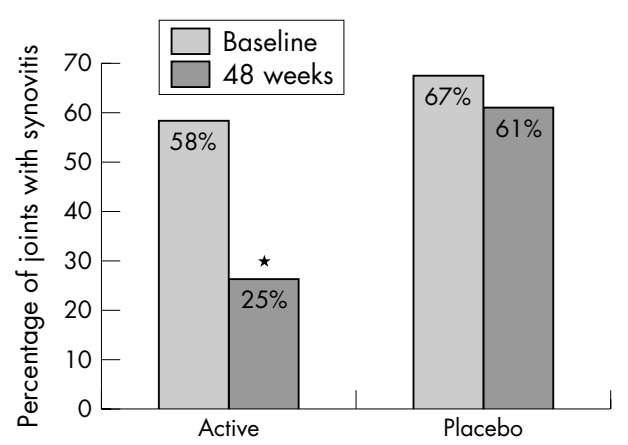

Figure 2 Percentage of joints with synovitis detectable by HRUS from baseline to 48 weeks. ${ }^{*} p<0.05$.

group 45/77 (58\%) joints assessed showed synovitis at baseline and 19/77 (25\%) at week $48(\mathrm{p}<0.05)$ (fig 2).

The mean dose of MTX at baseline and final assessment in the active group was 16.2 and $15.9 \mathrm{mg} /$ week, respectively, and in the placebo group was 15.8 and $15.7 \mathrm{mg} /$ week, respectively. The mean dose of CSA at baseline and final assessment in the MTX/CSA group was 2.48 and $2.25 \mathrm{mg} / \mathrm{kg} /$ day, respectively, and the placebo dosage was recorded as 2.49 and $3.45 \mathrm{mg} / \mathrm{kg} /$ day, respectively.

The mean (SD) serum creatinine concentration changed from baseline to 12 months from 92.2 to 99.5 (15.5) $\mu \mathrm{mol} / \mathrm{l}$ in the MTX/CSA group and from 82.1 to 88.6 (20) $\mu \mathrm{mol} / \mathrm{l}$ in the MTX/placebo group. The mean (SD) serum urea changed from baseline to 12 months from 1.7 to $2.4(0.8) \mathrm{mmol} / \mathrm{l}$ in the MTX/CSA group and from 1.4 to $1.3(0.3) \mathrm{mmol} / \mathrm{l}$ in the placebo group. Mean (SD) systolic blood pressure changed from 129 to 132 (14.7) $\mathrm{mm} \mathrm{Hg}$ in the MTX/CSA group and there was no recordable change in the MTX/placebo group. Mean (SD) diastolic blood pressure changed from 80.3 to 81.2 (9.5) $\mathrm{mmHg}$ in the MTX/CSA group and from 81.2 to 80.6 (10.3) $\mathrm{mm} \mathrm{Hg}$ in the MTX/placebo group. None of the changes in serum creatinine, serum urea, or blood pressure were significant.

Seven patients (18\%) in the MTX/CSA group and three $(9 \%)$ in the MTX/placebo group had hypertensive readings on at least one occasion. Table 3 shows that adverse events were recorded more frequently in the MTX/CSA group than in the placebo group. There was one (3\%) serious adverse event in the MTX/placebo group and four (11\%) in the MTX/CSA group, including one new diagnosis of ovarian carcinoma and one new diagnosis of interstitial lung disease.

Seventeen patients in the MTX/CSA group and 11 in the MTX/placebo group were withdrawn from the study before 6 months. Table 4 shows the reasons for withdrawal. The number of patients withdrawn from the study owing to an adverse event were $13(34 \%)$ in the MTX/CSA group and 2 $(6 \%)$ in the MTX/placebo group. Studies of CSA at high dose in organ transplantation have demonstrated frequent side effects such as hypertrichosis and gingivitis, which can interfere with clinical blinding. At doses used in arthritis and psoriasis, however, these side effects do not appear to be as common, despite careful surveillance, as confirmed by this and previous studies. ${ }^{8} 20$

\section{DISCUSSION}

Improvements in the swollen joint count and CRP were detected in the MTX/CSA treated group but not in the placebo group, and synovitis detected by HRUS was significantly reduced compared with placebo. This suggests that in patients with PsA who have only a partial response to MTX treatment the addition of CSA may offer clinically important benefits.

\begin{tabular}{|c|c|c|}
\hline & \multirow{2}{*}{$\begin{array}{l}\text { Placebo } \\
(n=34)\end{array}$} & \multirow{2}{*}{$\frac{\text { Ciclosporir }}{(n=38)}$} \\
\hline & & \\
\hline Nausea & $6(18)$ & $15(39)$ \\
\hline Headache & $2(6)$ & $9(24)$ \\
\hline Burning sensation & $0(0)$ & $5(13)$ \\
\hline Paraesthesia & $0(0)$ & $4(11)$ \\
\hline Muscle cramps & $0(0)$ & $4(11)$ \\
\hline Hypertrichosis & $0(0)$ & $3(8)$ \\
\hline Serious adverse event & 1 (3) & $4(11)$ \\
\hline
\end{tabular}

A more aggressive approach to the treatment of PsA has resulted not only in the earlier use of DMARDs and at higher doses but also, following the RA model, the proposed use of combination therapy. Tugwell et al studied the use of the combination MTX and CSA in RA and reported that it was statistically more effective than monotherapy with MTX, without any significant increase in toxicity. ${ }^{20}$ The combination of MTX and CSA in the treatment of PsA would appear intuitive as a step up for the patient with resistant/severe disease. Both agents are used for severe skin and joint disease, but with different and potentially complementary modes of action, which may result in therapeutic synergy. Specifically, MTX has important effects in PsA at the level of the synovium, including reducing synovial membrane infiltration with $\mathrm{T}$ cells and macrophages and the expression of proinflammatory cytokines. ${ }^{30}$ It is also now clear that cytokines are increased in PsA joint fluid and tissue and have a significant pathogenic role. ${ }^{31}$ Psoriasis and PsA are believed to be largely T cell mediated diseases, demonstrating greater levels of neovascularisation than are seen in RA owing to differential growth factor expression, ${ }^{32}$ and CSA is known to be a specific $\mathrm{T}$ cell inhibitor, with potent antiangiogenic properties. ${ }^{33}{ }^{34}$ Two previous uncontrolled studies have suggested additive efficacy without an increase in serious side effects when MTX and CSA are used together in PsA. ${ }^{21} 35$

Surprisingly, marked improvements in clinical outcomes were found in both the placebo group and the group receiving active treatment. Improvements in the placebo controlled groups of previous PsA studies, greater than those seen in RA studies, have been reported and summarised by Jones et al. ${ }^{36}$ This may reflect a cyclical pattern of symptomatology experienced by patients with PsA who may be recruited to studies during a symptom flare and consequently note some degree of spontaneous improvement. Despite this, improvements in SJC and CRP from baseline were noted in the MTX/ CSA group, and synovitis detected by HRUS was reduced

\begin{tabular}{|c|c|c|}
\hline & $\begin{array}{l}\text { Placebo } \\
(n=34)\end{array}$ & $\begin{array}{l}\text { Ciclosporin } \\
(n=38)\end{array}$ \\
\hline Abnormal laboratory values & $0(0)$ & $4(11)$ \\
\hline Abnormal test procedure results & $1(3)$ & $0(0)$ \\
\hline Change in medical condition & $1(3)$ & $5(13)$ \\
\hline Lost to follow up & $1(3)$ & 1 (3) \\
\hline Protocol violation & $1(3)$ & $2(5)$ \\
\hline Withdrawal of consent & $1(3)$ & 1 (3) \\
\hline Unsatisfactory therapeutic effect & $6(18)$ & $4(11)$ \\
\hline Total & $11(32)$ & $17(45)$ \\
\hline
\end{tabular}

Results are shown as No (\%). 
significantly in the MTX/CSA group as compared with the placebo group. It is not surprising from a pathophysiological viewpoint that these three measures appear to improve in a correlated fashion as SJC is a clinical measure of joint synovitis, serum CRP levels will reflect total body synovial mass, and HRUS is an objective and sensitive tool for detecting and quantifying synovitis. Consequently, the most convincing evidence for efficacy relates to the HRUS as opposed to purely clinical measures.

Greater synovial activity might be expected to result in greater bony change, but despite a deterioration in the Larsen score in the MTX/placebo group of over $20 \%$ versus $5 \%$ in MTX/CSA, this difference was not significant. It would appear therefore that adding CSA to MTX in active PsA has resulted in a significant reduction in inflammation not seen in the placebo controlled group. A highly significant improvement in the PASI score of patients in the MTX/CSA group compared with the MTX/placebo group was noted, demonstrating a beneficial additive efficacy in psoriasis and confirming the additive benefit of these agents in the treatment of skin psoriasis at least.

Despite this, no significant improvements were demonstrated in either patient global assessments of pain or disease activity or indeed quality of life. It may be argued that this supports a disassociation between the presence of synovitis and symptoms in PsA. Undoubtedly, the high level of spontaneous improvement in the MTX/placebo group and a degree of underrecruitment resulted in this study being underpowered, despite some clinical benefits from combining CSA with MTX being demonstrated. The risk of a type II error has to be considered to be significant and conclusions, apart from the positive benefits demonstrated, should be guarded for the reasons outlined above.

Fewer patients in the MTX/CSA group completed the study than in the MTX/placebo group and there were more drug related adverse events in the MTX/CSA group than in the MTX/placebo group. These figures reflect previously published data, which point towards some increase in toxicity, resulting in higher dropout rates for CSA than MTX. ${ }^{28}$

It would appear that etanercept is currently the only therapeutic agent with sufficient data from placebo controlled, randomised studies to receive a Food and Drug Administration indication for the treatment of PsA in America. ${ }^{37}$ Despite this, few people currently recommend the use of anti-tumour necrosis factor $\alpha$ as first line treatment for PsA and, consequently, we need to develop our evidence base for the implementation of escalating treatment in difficult/aggressive PsA before the use of biological agents.

In this study we demonstrate clinical benefits shown by reduced levels of inflammation at 12 months in patients with active PsA. It would appear that combination therapy with CSA and MTX in patients with active PsA and persistent inflammation despite adequate monotherapy with DMARDs, is a valid therapeutic option for the reduction of synovitis.

\section{ACKNOWLEDGEMENTS}

We gratefully acknowledge the contribution of Sister Geraldine Jackson, rheumatology research sister at the department of academic rheumatology, Leeds.

This study was supported by Novartis Pharma AG.

\section{Authors' affiliations}

A D Fraser, Z Karim, R Wakefield, P Emery, D J Veale, Rheumatology and Rehabilitation Research Unit, University of Leeds, LS3 9NZ, UK A W R van Kuijk, A H Gerards, B A C Dijkmans, VU Medical Centre, Amsterdam, The Netherlands R Westhovens, University of Leuven, Leuven, Belgium R Landewé, University Hospital Maastricht, Maastricht, Netherlands S D Steinfeld, Erasme University Hospital, Brussels, Belgium

\section{REFERENCES}

1 Veale D, Rogers $S$, Fitzgerald $O$. Classification of clinical subsets in psoriatic arthritis. Br J Rheumatol 1994;33:133-8.

2 Kane D, Stafford L, Bresnihan B, FitzGerald O. A prospective, clinical and radiological study of early psoriatic arthritis: an early synovitis clinic experience. Rheumatology (Oxford). 2003;42: 1460-8, Epub 1 October 2003.

3 Espinoza LR. Psoriatic arthritis: further epidemiological and genetic considerations. In: Gerber LH, Espinoza LR, eds. Psoriatic arthritis. Orlando: Grune and Satton, 1985:9-32.

4 Gladman DD, Shuckett R, Russell ML, Thorne JC, Schachtner RK. Psoriatic arthritis (PsA) - an analysis of 220 patients. Q J Med 1987;238:127-41.

5 Gladman DD, Stafford-Brady F, Chang CH, Lewandowski K, Russell ML. Longitudinal study of clinical and radiological progression in psoriatic arthritis. $J$ Rheumatol 1990;17:809-12.

6 Wong K, Gladman DD, Husted J, Long JA, Farewell VT. Mortality studies in psoriatic arthritis: results from a single outpatient clinic. Causes and risk of death. Arthritis Rheum 1997;40:1868-72.

7 FitzGerald O, Kane D. Clinical, immunopathogenetic, and therapeutic aspects of psoriatic arthritis. Curr Opin Rheumatol 1997;9:295-301.

8 Heydendael VMR, Spuls PI, Opmeer BC, de Borgie CAJM, Reitsma JB, Goldschmidt WFM, et al. Methotrexate versus cyclosporine in moderate-tosevere chronic plaque psoriasis. N Engl J Med 2003;349:658-65.

9 Black RL, O'Brien WN, Van Scott EJ, Auerbach R, Eisen AZ, Bunim JJ. Methotrexate therapy in psoriatic arthritis. JAMA 1964;189:743-7.

10 Kragballe K, Zachariae E, Zachariae H. Methotrexate in psoriatic arthritis: a retrospective study. Acta Derm Venereol 1983;63:165-7.

11 Willkens RF, Williams HJ, Ward JR, Egger MJ, Reading JC, Clements PJ. Randomized, double blind, placebo controlled trial of low-dose pulse methotrexate in psoriatic arthritis. Arthritis Rheum 1984;27:376-81.

12 Zachiariae H, Zachariae E. Methotrexate treatment of psoriatic arthritis. Acta Derm Venereol 1987;67:270-3.

13 Espinoza LR, Zakraoui L, Espinoza CG, Gutierrez F, Jara L, Silviera LH, et al. Psoriatic arthritis: clinical response and side effects to methotrexate therapy. J Rheumatol 1992;19:872-7

14 Gupta AK, Matteson EL, Ellis CN, HO VC, Tellner DC, Voorhees JJ, et al. Cyclosporine in the treatment of psoriatic arthritis. Arch Derm 1989; 125:507-10.

15 Kokelj F, Lavaroni G, Stinco G. Psoriatic arthritis treated with cyclosporin A. Allerg Immunol (Paris) 1992;24:393-4.

16 Wagner SA, Peter RU, Adam O, Ruzicka T. Therapeutic efficacy of oral lowdose cyclosporin A in severe psoriatic arthritis. Dermatology 1993;186:62-7.

17 Riccieri V, Sili Scavalli A, Spadaro A, Bracci M, Taccari E, Zoppini A. Shortterm cyclosporin A therapy for psoriatic arthritis. Acta Derm Venereol Suppl (Stockh) 1994;186:94-5.

18 Little CB, Hughes CE, Curtis CL, Jones SA, Caterson B, Flannery CR. Cyclosporin $A$ inhibition of aggrecanase-mediated proteoglycan catabolism in articular cartilage. Arthritis Rheum 2002;46:124-9.

19 Mahrle G, Schulze HJ, Brautigam M, Mischer P, Schopf R, Jung EG, et al. Anti-inflammatory efficacy of low-dose cyclosporin $A$ in psoriatic arthritis. $A$ prospective multicentre study. Br J Dermatol 1996;135:752-7.

20 Tugwell P, Pincus T, Yocum D, Stein M, Gluck O, Kraag G, et al. Combination therapy with cyclosporine and methotrexate in severe rheumatoid arthritis. N Engl J Med 1995;333:137-41

21 Mazzanti G, Coloni L, De Sabbata G, Paladini G. Methotrexate and cyclosporine combined in severe psoriatic arthritis. A pilot study. Acta Derm Venereol Suppl (Stockh) 1994;186:116-17.

22 Felson DT, Anderson JJ, Boers M, Bombardier C, Chernoff M, Fried B, et al. The American College of Rheumatology preliminary core set of disease activity measures for rheumatoid arthritis clinical trials. Arthritis Rheum 1993;36:729-40

23 Fredriksson $T$, Pettersson U. Severe psoriasis - oral therapy with a new retinoid. Dermatologica 1978;157:238-44.

24 Fries JF, Spitz PW, Young DY. The dimensions of health outcomes: the Health Assessment Questionnaire, disability and pain scales. J Rheumatol 1982;9:789-93.

25 Larsen A, Dale K, Eek M. Radiographic evaluation of rheumatoid arthritis and related conditions by standard reference films. Acta Radiol Diagn 1977;18:481-91.

26 Backhaus M, Kamradt T, Sandrock D, Loreck D, Fritz J, Wolf KJ, et al. Arthritis of the finger joints: a comprehensive approach comparing conventional radiography, scintigraphy, ultrasound, and contrast enhanced magnetic resonance imaging. Arthritis Rheum 1999;42:1232-45.

27 Grassi W, Lamanna G, Farina A, Cervini C. Synovitis of the small joints: sonographic guided diagnostic and therapeutic approach. Ann Rheum Dis 1999;58:595-7.

28 Spadaro A, Riccieri V, Sili Scavalli A, Sensi F, Taccari E, Zoppini A. Comparison of cyclosporin $A$ and methotrexate in the treatment of psoriatic arthritis: a one-year prospective study. Clin Exp Rheumatol 1995; 13:589-93.

29 Salvarani C, Macchioni P, Olivieri I. A comparison of cyclosporine, sulfasalazine, and symptomatic therapy in the treatment of psoriatic arhtrits. J Rheumatol 2001;28:2274-82.

30 Kane D, O'Leary J, Gogarty M, Da Silva, Bermngham N, Bresnihan B, Fitzgerald $O$. The therapeutic benefit of methotrexate in psoriatic arthritis is mediated by a reduction in synovial inflammatory infiltrate and cytokine expression, but not vascularity [abstract]. Rheumatology (Oxford) 2001;40:S10.

31 Fraser A, Fearon U, Billinghurst RC, lonescu M, Reece R, Barwick T, et al. Turnover of type II collagen and aggrecan in cartilage matrix at the onset of inflammatory arthritis in humans. Arthritis Rheum 2003;48:3085-95. 
32 Fearon U, Griosios K, Fraser A, Reece R, Emery P, Jones PF, et al. Angiopoietins, growth factors, and vascular morphology in early arthritis. J Rheumatol 2003;30:260-8.

33 Iuralaro $M$, Vacca $A$, Minischetti $M$, Ribatti $D$, Pellegrino $A$, Sardanelli, et al. Antiangiogenesis by cyclosporine. Exp Hematol 1998;26:1215-22.

34 Lorenz HM. T-cell inhibitors in rheumatoid arthritis. BioDrugs 2003; 17:263-70.
35 Clark CM, Kirby B, Morris AD, Davison S, Zaki I, Emerson R, et al. Combination treatment with methotrexate and cyclosporine for severe recalcitrant psoriasis. Br J Dermatol 1999;141:279-82.

36 Jones G, Crotty M, Brooks P, and the Psoriatic Arthritis Meta-Analysis Study Group. Psoriatic arthritis: a quantitative overview of therapeutic options. $\mathrm{Br} J$ Rheumatol 1997;36:95-9.

37 Gladmann DD. Effectiveness of psoriatic arthritis therapies. Semin Arthritis Rheum 2003;33:29-37.

\section{$\mathrm{ECHO}$}

\section{Active format teaches physiotherapists to follow evidence based care}

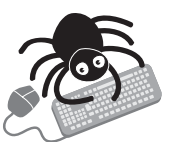

Please visit the Annals of the Rheumatic Diseases website [www. annrheumdis. com] for a link to the full text of this article.

\section{$P$} hysiotherapists are better at putting guidelines for treating low back pain into practice if these are introduced in an active, wide ranging programme, a randomised controlled trial has reported, for the first time.

Physiotherapists who had been through the programme were twice as likely to comply with the evidence based guidelines-like ordering fewer treatment sessions for patients with a normal course of lower back pain and recommending active interventions and functional treatment goals - as those who had not. They were over three times as likely to engage in sufficient patient education.

The effect was modest, but the researchers suggest that the volunteer status of all physiotherapists in the trial_-and their enthusiasm for evidence based care-may mask the true difference. Nevertheless, the results still showed that physiotherapists must resist overtreating those patients with a normal course to their back pain.

The participants were from 68 private primary care physiotherapy practices agreeing to take part of those randomly selected by the Royal Dutch Society for Physiotherapy. Fifty two physiotherapists were randomly allocated to the active programme, and 61 merely received the guidelines in a standard mailing. The care process was assessed from each patient's treatment forms by blinded independent assessors. Results for 37 (48) physiotherapists and 247 (253) patients were analysed, respectively.

Evidence based guidelines for physiotherapists' care of generalised back pain have been sent to all physiotherapists in the Netherlands. The trial sought to test the usefulness of the active programme already devised to improve their implementation. 